\title{
Stadyum İlişkili Hırsızlık Suçunun Mekânsal- Zamansal Analizi: İngiliz Örnekleminde Olay İncelemesi
}

\author{
Spatiotemporal Analysis of Stadium-Related Theft: An English \\ Case-Study
}

\section{Derya TEKİN ${ }^{1}$ (@) Justin KURLAND ${ }^{2}$ (])}

${ }^{1}$ Dr. Öğr. Üyesi, İstanbul Medeniyet Üniversitesi Hukuk Fakültesi, Ceza ve Ceza Muhakemesi Anabilim Dalı, İstanbul Türkiye

${ }^{2}$ Assoc. Prof. Dr., National Center for Spectator Sports Safety and Security, The University of Southern Mississippi, USA

ORCID: D.T. 0000-0001-9877-8336; J.K. 0000-0001-9546-4307

\section{öz}

Futbola ilişkin akademik çalışmalar, çoğunlukla, şiddet suçlarını ve bu suçları işleyen taraftarları konu edinmiştir. Geleneksel kriminolojinin futbol kontekstine bir yansıması olarak düşünülebilecek bu çalışmalardan farklı olarak bu araştırma, hırsızlık suçlarının maç günlerinde nerede ve ne zaman ortaya çıkabileceğine odaklanan suç desenlerini ve bu desenlerin neden ortaya çıkabileceğini incelemektedir. Çevresel kriminolojinin birbiriyle bağlantılı teorilerinden rutin aktiviteler teorisi ile suç deseni teorisi, bu çalışmanın teorik çerçevesini oluşturmaktadır. Bu iki teori sosyal ve fiziksel çevrenin bileşenlerinin stadyum ilişkili hırsızlık suçu için gerekli şartları nasıl sağladığını başarılı bir şekilde göstermektedir. Metodolojik olarak hırsızlık suçlarının mekânsal analizi için Kernel Yoğunluk Tahmini ve uzaysal permütasyon testi kullanılmış, zamansal analiz içinse bir "maç ayarlı zamansal analiz" geliştirilmiştir. Leeds United futbol takımının Elland Road Stadyumu çevresinde sıcak noktalama tekniği uygulanarak hırsızlık suçlarının zamanda (maç günlerinde ve maç olmayan günlerde) ve mekânda rastgele dağılmadığı ortaya konulmuştur. Stadyum ilişkili hırsızlık suçlarının zamansal ve mekânsal analizi, istihbarat hizmetlerine bilgi sağlayarak güvenlik görevlilerinin ne zaman ve nerede konuşlanması gerektiği konusunda bir rehber olarak kullanılabilecektir.

Anahtar Kelimeler: Stadyum ilişkili suç, Hırsızlık, Sıcak noktalama, Suçönleme, Suç deseni teorisi, Rutin aktiviteler teorisi

\section{ABSTRACT}

Academic studies on football-related crimes have predominantly focused on violent crimes and fans engaged in these crimes. Unlike these studies which may be deemed a reflection of the traditional criminology in the football context, this paper examines the crime patterns focused on where and when theft crimes might occur on match days and why such patterns might emerge. Routine activities theory and crime pattern theory which are two related theories of environmental criminology provide a theoretical framework for the study. These two theories successfully reveal how the components of the social and physical environment provide the necessary conditions for stadium-related theft. Methodologically, for the spatial analysis of theft crimes, the methods of Kernel Density Estimation and spatial permutation test are employed; for the temporal analysis, a "match adjusted temporal analysis" is developed. Using the hotspotting technique around the Elland Road Stadium of Leeds United football team, it is suggested that theft crimes are not randomly distributed in time (match days and non-match days) and space. The risk of theft (per unit of time) is found to be particularly elevated at certain locations near to the stadium on match days, and for a window of time before, during and after matches take place. Analysing the spatial and temporal dimensions of stadium-related theft crime is likely to provide guidance about when and where to deploy officers by informing intelligence services.

Keywords: Stadium-related crime, Theft, Hotspotting, Crime prevention, Crime pattern theory, Routine activities theory

Submitted: 20.09 .2019 - Accepted: 11.12.2019 • Published Online: 31.12 .2019

Corresponding author: Derya Tekin, E-mail: tekin_derya@hotmail.com

Citation: Tekin D, Kurland J, 'Stadyum İlişskili Hırsızlık Suçunun Mekânsal-Zamansal Analizi: İngiliz Örnekleminde Olay İncelemesi' (2019) 7(2) Ceza Hukuku ve Kriminoloji Dergisi-Journal of Penal Law and Criminology, 233. 


\section{EXTENDED ABSTRACT}

Crime associated with football dates back to the Middle-Ages. There have been diverse attempts at explanation and prevention, which go back just as far and largely mirror the concerns of traditional criminology insofar as the focus has been on underlying biological developmental, social and political conditions thought liable to foster the motivation of "hooligans". However, little exists in the way of empirical research to determine whether these explanations are sufficient or whether preventive interventions have been effective. The problems persist and anecdotal evidence suggests that crime events other than just violence are associated with football matches continue within and beyond stadiums. In this paper we adopt a novel perspective that utilizes the framework of environmental criminology whose principle concern is patterns of crime events focusing not on who engages in crime but on where and when crime occurs on football match days and why such patterns might emerge. The approach is also pragmatic and so findings are interpreted in terms of what can be done in the relatively short term to deal with football-related crime. The paper is organized as follows. First, we briefly discuss the history of interventions to suppress the game and the associated violence often associated with the game. Second, we discuss two theoretical frameworks, which are routine activities theory and crime pattern theory, and how they might inform our understanding of patterns of crime in and around football grounds and briefly indicate how these frameworks have been applied to forecast and prevent crime. The first, "routine activity theory" provides insight into why and where crime might occur on football match days and proposes that crime is dependent on the convergence in space and time of (1) a likely offender (someone motivated to commit crime), (2) a suitable target (someone or something that the likely offender will be attracted to offend against) and (3) the lack of a capable guardian (someone who is able and empowered to protect the target). Changes in the availability of any of these groups affect the likelihood of crime. Crime pattern theory, on the other hand, focuses on spatial patterns of crime and how they emerge. Offenders, like everyone else, engage in routinized patterns of activity, repeatedly travelling to and from various nodes of activity, such as work, school, home, or entertainment facilities. This regularity of movement leads people to develop activity spaces consisting of their activity nodes and the routes between them with which they become familiar. Potential offenders develop an awareness of criminal opportunities within these activity/awareness spaces, which furnishes them with knowledge as to the likely risks, effort and rewards associated 
with exploiting them. The theory suggests that a crime could occur as a result of the interaction between offender and victim at a number of activity nodes (pub, fast-food restaurant and stadium) or the paths between them. When matches are played the change in the ecology of the areas around stadiums may facilitate the confluence of many potential victim/offender activity spaces that under normal conditions would not occur. Third, we address some questions about patterns of stadium-related crime events such as, "Do hotspots of football-related crime emerge around stadiums on match days and, if so, where?" and, related to this, "Do such hotspots (if they occur) appear in the same places (and times) on match and non-match days"? To address these questions and illustrate the utility of the approach, an empirical example related to theft offences in and around a stadium, the Elland Road Stadium of Leeds United football team, is presented. Methodologically, for the spatial analysis of theft crimes, the methods of Kernel Density Estimation and spatial permutation test are employed; for the temporal analysis, a "match adjusted temporal analysis" is developed. Last, the results, their implications, and methodological issues associated with traditional hotspotting techniques are discussed. The research suggests that theft crimes are not randomly distributed in time (match days and non-match days) and space. The risk of theft (per unit of time) is found to be particularly elevated at certain locations near to the stadium on match days, and for a window of time before, during and after matches take place. Analysing the spatial and temporal dimensions of stadium-related theft crime is likely to provide guidance about when and where to deploy officers by informing intelligence services.

\section{Giriş}

Futbola ilişkin suçun tarihi Orta Çağ'a kadar uzanır (Elias ve Dunning, 1971). Bu olgunun açıklanması ve önlenmesine dair çeşitli girişimlerde bulunulmuştur. Öyle ki bu girişimler, "holiganların" suç motivasyonunu beslediği düşünülen biyolojik (Buford, 1991), gelişimsel (Marsh, 1978), sosyal (Armstrong, 1998) ve politik (Taylor, 1971) şartlar üzerinde odaklandığı sürece, geleneksel kriminolojinin ilgi alanına da büyük ölçüde ayna tutmuş olmaktadırlar. Bununla birlikte, bu açıklamaların yeterli olup olmadığını ya da önleyici müdahalelerin etkili olup olmadığını belirleyecek çok az ampirik (gözlemsel) araştırma mevcuttur (De Vreese, 2000; Lösel ve Bliesener, 2003). Futbola ilişkin suç problemi varlığını sürdürmekte (Frosdick ve Marsh, 2005) ve anekdotsal kanıtlar (Home Office, 2004-2009) şiddet dışındaki suç olaylarının da futbol maçlarıyla ilişkili olarak stadyum içinde ve çevresinde devam ettiğini 
göstermektedir. Bu çalışmada, futbol maç günleri suça kimin karıştığına değil, nerede ve ne zaman suçun ortaya çiktığına odaklanan suç desenlerini ve bu desenlerin neden ortaya çıkabileceğini konu edinen çevresel kriminolojinin çerçevesinden yararlanan özgün bir bakış açısı benimsiyoruz. Bu yaklaşım aynı zamanda pragmatik bir yaklaşımdır. Bu nedenle bulgularımız, futbolla ilişkili suçlarla mücadelede, nispeten kısa vadede, neler yapılabileceği noktasında yorumlanacaktır.

Makale şu şekilde organize edilmiştir. İlk olarak, futbol oyununu ve s1k sık oyunla ilişkilendirilen şiddeti kontrol altına almak için yapılan müdahalelerin tarihi kısaca ortaya konulacaktır. İkinci olarak, iki kuramsal çerçevenin stadyumlarda ve çevrelerindeki suç desenleri anlayışımızı nasıl şekillendirebilecekleri ve bunların suçu tahmin etmek ve önlemek için nasıl uygulamaya geçirilebilecekleri tartışılacaktır. Üçüncü olarak, futbolla ilişkili suç olay desenleri ile ilgili bazı sorular ele alınacaktır: "Futbolla ilişkili suçların sıcak noktaları (hotspots) stadium çevresinde maç günleri mi ortaya çıkar ve eğer öyleyse bu noktalar nerededir?", yine bu soruyla ilişkili şekilde "Bu sıcak noktalar (eğer ortaya çıkmışlarsa) maç günleri ile maç olmadığı günler (non-match days) aynı yerlerde mi görünürler?” Bu soruları cevaplayabilmek ve benimsediğimiz yaklaşımın amaca uygunluğunu ortaya koymak için, belirli bir stadyumun içinde ve çevresinde işlenen hırsızlık suçlarıyla ilgili ampirik bir örnek sunulacaktır. Son olarak sonuçlar, bunların yansımaları ve geleneksel sıcak noktalama tekniklerine (traditional hotspotting techniques) ilişkin metodolojik sorunlar tartışılacaktır.

\section{Arka Plan}

Britanya'da adlandırıldığı üzere Orta Çağ’a özgü "halk futboluna (folk football)" dair kanıtlar seyirciler ve oyuncular arasındaki şiddetin sıklıkla ciddi yaralanmalara ve özel ya da kamusal mülkiyete yönelik zarara yol açtığını ortaya koymaktadır (FitzStephen, 1961; Dunning vd., 1988). Öyle ki bu durum, oyunu yasaklamak için bazı resmi önlemlerin getirilmesine dahi yol açmıştır. Bundan dolayıdır ki, İngiltere'de 1314 ile 1496 yılları arasında futbolun bu Orta Çağ versiyonunu yasaklamak için çok sayıda devlet düzeyinde kararname ve tüzük çıkarılmıştır (Dunning, 1999; Magnoun, 1938; Marples, 1954; Strutt, 1801). Orta Çağ'da ortaya çıkan bu futbola ilişkin şiddet ve düzensizlik olgusunun ülkesel ve yerel kararnamelere rağmen modern çağda da varlığını sürdürmesi (Marples, 1954; Dunning vd., 1988; Russell, 2004) söz konusu önlemlerin etkinliği konusunda şüphe uyandırmaktadır. Gerçekten de, 1960'lı yıllar ve sonrasında Birleşik Krallık’ta yaygın futbolla ilişkili şiddet ve düzensizlik modern yasa koyucuları, uygulayıcıları ve araştırmacıları spora ilişkin şiddeti azaltmak için yeni ve daha etkili 
yollar bulmaya teşvik etmiştir. Örneğin, 1970 ve 1980'li yıllarda şiddet eğilimli seyirci topluluklarının sahayı işgal etme riski stadyumlara yüksek tel örgülerin yerleştirilmesine zemin hazırlamıştır. Bu önlem aynı zamanda sadece İngiltere'de değil, Avrupa ve Güney Amerika stadyumlarında da yaygın hale gelen bir diğer düzensizlik şekli olan sahaya yabancı madde atımını azaltmayı hedeflemekteydi. Bu yüksek metal tel örgüler, çoğu zaman, rakip taraftarların birbirleri ile fiziksel temasını önlemeye yarayan ve böylece rakip taraftarların serbestçe dolaşması halinde meydana gelebilecek kaosları azaltacak geniş bir dörtgen kafes sisteminin parçasıydılar (Harrison, 1974). O sıralar, Birleşik Krallık'ta kitlesel medya ve diğer bazı otoriteler alkolün şiddetin ana etkeni olduğunu iddia ettiler. Bu durum maç sırasında stadyum içerisinde alkolün dağııımını ve tüketimini yasaklayan ya da sınırlayan para cezaları veya üç aya varan hapis cezaları aracılığıyla caydırıcı etki yaratacak ve alkolün etkisiyle gelişen olayları önleyecek bir araç işlevi görecek çeşitli yasaların geçirilmesine temel teşkil etti.

1980'lerde çok sayıda insan ölümlerine neden olan trajik stadyum olaylarını takiben İngiltere'de, ayakta durulan tribünlerin aşırı kalabalıklaşmayı önleyecek ve ezilme riskini bertaraf edecek koltuklu tribünlere dönüştürülmesini zorunlu kılan yasalar çıkarılmıştr. Türkiye de benzer şekilde, bilet satışlarının ancak koltuk numarasıyla ilişkilendirilerek yapılacağını sporda şiddet ve düzensizliğin önlenmesine dair çıkardığ 1 kanunlarda (5149 ve 6222 sayılı Kanun) hüküm altına almıştır. Dahası, bu uygulamaların olası önleyici etkileri, örneğin güvenlik görevlileri ve CCTV kameraları için daha iyi görüş alanı yaratarak seyirciler üzerindeki resmi gözetimin güçlendirilmesi, kurallara aykırı taraftar davranışlarının tespit edilmesini de mümkün kılmaktadır. Benzer bir yaklaşım Türkiye'de de benimsenmiş ve futbol taraftarlarınca da genel olarak kabul görmüştür (Tekin, 2019).

Seyirden yasaklama kararlarına temel teşkil eden yasalar da yine bu dönemde kaleme alınmıştır. Sadece birkaç "çürük elma (rotten apple)" diye tabir edilen taraftarın futbolu berbat ettiği inancından hareketle, futbolda şiddet ve düzensizliği önlemek için bu kişileri tespit etmenin ve maça girişlerini önlemenin gerekliliği gündeme geldi. Seyirden yasaklama kararları genel olarak kişilerin maçların oynandığı saatlerde yerel polis merkezlerine bildirimde bulunmasını ve böylece bu kişilerin maç günlerinde hareket özgürlüklerinin kısıtlanmasını içermektedir. Yurtdışında oynanan maçlar söz konusu olduğunda ise, yasaklı taraftarlar pasaportlarını belirli bir süre için yetkililere teslim etmek zorundadırlar. Türkiye kontekstinde de seyirden yasaklama ve seyirden yasaklanma tedbirleri olarak adlandırılan benzer uygulamalar mevcuttur. 
Seyirden yasaklamanın İngiliz taraftarlar üzerinde ve daha çok da uluslararası kontekste etkililiğini değerlendirmeye tabi tutan çalışmalar mevcuttur. Örneğin Stott ve Pearson (2006) seyirden yasaklama kararlarının, yasaklı taraftarlar uluslararası maçlarda İngiltere'de kalmış olsa dahi, şiddeti önlemede etkisiz bir tedbir olduğunu ileri sürmüşlerdir. Seyirden yasaklama üzerine benzer bir değerlendirme İskoçya kontekstinde Bradford vd. (2011) tarafından da yapılmış ve bu çalışma seyirden yasaklamanın etkililiğine dair karışık deliller sunsa da, uygulayıcılar arasındaki genel kanının, bu tedbirin birden fazla kez tutuklanmış taraftarlar açısından etkili olduğu yönünde olduğunu ortaya koymuştur.

Seyirden yasaklama karaları istisna olmak üzere, diğer şiddeti önlemeye yönelik taktikler İngiltere'de ampirik olarak test edilememiştir. Bunu ana sebebi stadyum çevresinde gerçekleşen tutuklamalara, suç olaylarına ve polis müdahalelerine yönelik güvenilir veri eksikliğidir (Frosdick ve Marsh, 2005). Bu durum rahatsız edicidir çünkü 10 yılı aşkın süredir Birleşik Krallık İçişleri Bakanlığı (UK Home Office) tarafindan y1llık olarak toplanan ve futbolla ilişkili tutuklama figürlerine dair tek ulusal düzeydeki veri setinin gösterdiği üzere futbolla ilişkili suç problemi varlığını sürdürmektedir (bkz. Kurland, 2014).

Bu zamana kadar, tartışma konusu yapılan futbolla ilişkili suç ve düzensizliklerin çoğunluğu şiddet suçlarıdır. Bununla birlikte, stadyum dışında meydana gelen olaylarla ilişkilendirilen diğer kategorilerdeki suçlar da literatürde belirlenmiştir. Örneğin yaşam öyküsü metodu ile yapılan bir çalışma geniş taraftar gruplarının nasıl lisanslı ürün satan belirli mağazalara girerek mümkün derecede en fazla ürünü nasıl çaldıklarını ortaya koymuştur (Brown ve Brittle, 2008). Dahası, Buford (1991) yaklaşık dört bin İngiliz taraftarın İtalya'daki 1990 Dünya Kupası sırasında Cagliari kentine ne kadar korkunç bir şekilde zarar verdiğini betimlerken, stadyum sınırları dışında gerçekleşen futbolla ilişkili suçlara dair çarpıcı tespitler sunmuştur: taraftarlar konutların ve mağazaların camlarını kırmış, arabaları parçalamış, trafiği durdurmuş, yolda gördükleri masum kişilere saldırmış ve polisle çatışmıştır. Konu ile ilgili daha güncel ampirik bir çalışma Kurland, Johnson ve Tilley (2014) tarafından gerçekleştirmiştir. Yazarlar, Wembley Ulusal Stadyum'unun çevresinde meydana gelen hırsızlık ve bulundurma suçlarının (handling offences) sayısının ve dağılımının maç günlerinde stadyumun kullanımda olmadığı günlere kıyasen değişiklik arz ettiğini ortaya koymuşlardır. $\mathrm{Bu}$ tespitin İngiltere'deki diğer stadyumlarda ve diğer ülkelerdeki stadyumlarda geçerliliği belli olmamakla beraber, bu durum daha fazla akademik incelemeyi hak eder bir 
olgudur. Leeds United stadyumu içinde ve çevresinde meydana gelen hırsızlık olaylarını konu edinen bu makalenin amacı da budur.

Sonraki kısımda bu çalışmaya temel teşkil eden ve futbola ilişkin sıcak nokta (hotspot) çalışmalarını teşvik eden teorik altyapı tartışılacaktır. Aynı zamanda sıcak noktalama politikasının diğer kontekstlerdeki etkinliğine ve bu çalışmanın futbola ilişkin suçu anlama ve önleme noktasında nasıl katkı sağlayabileceğine de kısaca değinilecektir.

\section{Teorik Altyapı}

Çevresel kriminolojinin birbiriyle bağlantılı iki teorisi, sosyal ve fiziksel çevrenin bileşenlerinin futbolla ilişkili suç için gerekli koşulları sağladığını göstermektedir. Bunların ilki, futbol maçlarının olduğu günlerde neden ve nerede suçun ortaya çıkabileceğine dair bilgi sağlayan rutin aktiviteler teorisidir (Felson ve Cohen, 1980; Kurland, Tilley ve Johnson 2018; Madensen ve Eck, 2011). Teori, suçun ortaya çıkmasının (1) potansiyel failin (suç işlemek için motive olmuş bir kişi), (2) uygun bir hedefin (potansiyel fail tarafından suç işlemek için seçilebilecek bir kişi veya şey) ve (3) ehil bir gardiyanın eksikliğinin (suçun hedefindeki kişi veya şeyi koruyabilecek ve bunun için yetki verilmiş bir kişi) belirli bir zaman ve mekânda karşılaşmasına bağlı olduğunu ileri sürer. Bu gruplardan herhangi birinin mevcudiyetindeki değişiklikler suç olasılığını etkileyecektir. Bunlara ek olarak teori, bazı aktörlerin de suçun önlenmesi ve güvenliğin sağlanması noktasında kilit rol oynayabileceğini ifade eder: (1) tutucular (handlers), yani potansiyel failler üzerinde kontrol sağlayabilecek ebeveynler, öğretmenler ya da arkadaşlar (Felson, 1986; Felson, 1995), ve (2) mekân yöneticileri (place managers), yani belirli mekânların idare edilme şeklinin yanı sıra bu mekânları kullananlar üzerinde de etkili olabilecek kişiler, örneğin bar çalışanları, futbol stadyumlarının içindeki büfelerde çalışan kişiler (Eck, 1994).

$\mathrm{Bu}$ çekirdek rutin aktivite unsurları görsel olarak Figür 1'de sunulmuştur. İçteki üçgen fail, hedef ve suç yerini temsil eder ve suçun ortaya çıkması için bu üçünün - ehil gardiyanın yokluğunda - bir araya gelmesi gerektiğini gösterir. Herhangi bir unsurun yokluğunda suç ortaya çıkmayacaktır (Eck, 2003). Dış üçgen suç problemini bastırabilecek denetleyicileri (controllers) temsil eder ve her bir tipteki denetçinin kimler üzerinde nüfusunu kullanabileceğini gösterir (Clarke ve Eck, 2005; Scott, Eck, Knuttson ve Goldstein, 2008). Bu yaklaşım futbola ilişkin suç ve düzensizlik bakımından pratik bir değere sahiptir. Faillerin, hedeflerin, gardiyanların ve yöneticilerin maç günleri rutin 
aktivitelerini anlamak futbola ilişkin suç ve düzensizliğe katkı yapan faktörlerin ve bunların önlenmesi için yapılması gerekenlerin belirlenmesine yardımcı olur.

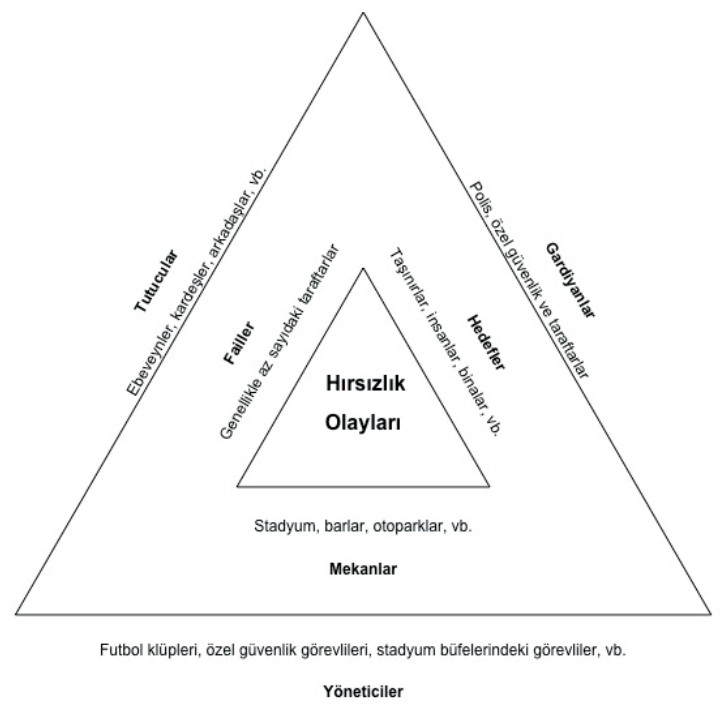

Figür 1. Futbola ilişkin suç ve düzensizliğin rutin unsurları (Madensen ve Eck, 2012'den uyarlanmıştır)

Brantingham ve Brantingham'1n (1981) "suç deseni teorisi” (crime pattern theory) ise suçun zamansal desenleri ve bunların nasıl ortaya çıktığı üzerinde odaklanır. Failler, diğer herkes gibi, iş, okul, ev ve eğlence merkezleri gibi aktivite düğüm noktaları (nodes) arasında defalarca gidip gelirken rutinleşmiş aktivite desenleri ile meşgul olurlar. Bu düzenli yer değiştirme faaliyeti insanları, kendi aktivite düğüm noktalarını ve bunlar arasındaki tanıdık güzergâhları içeren aktivite alanlarını (activity spaces) geliştirmeye yönlendirir. Potansiyel failler de aynı şekilde bu aktivite alanları içinde ve bu alanları kötüye kullanmalarına ilişkin olası riskler, çabalar ve getiriler hakkında bilgi sağlayan bir suç firsatları bilinci/farkındalığı geliştirirler (Brantingham ve Brantingham, 1993; Rossmo, Laverty ve Moore, 2004). Farkındalık, bir suçun işlenmesine ilişkin belirsizliği azaltacağından (Cornish ve Clarke, 1986), suç olayları faillerin farkındalık alanlarını (awareness spaces) kötüye kullanabilecekleri suç firsatları ile kesişince ortaya çıkacaktır (Brantingham ve Brantingham, 1975; Brantingham ve Brantingham, 1981; Reppetto, 1974). Ve ampirik araştırmaların da desteklediği üzere, suçlar aktivite dügüum noktalarındaki ya da bunların yakınlarındaki fail aktivite alanları (offender activity spaces) etrafında daha yüksek yoğunlukta toplanacaktır (Brantingham 
ve Brantingham, 2008; Rossmo, 2000; Townsley ve Sidebottom, 2010). Zamanla, faillerin farkındalık alanları yeni arkadaşlar edindikçe, taşındıkça ya da yeni aktivitelerle meşgul olmaya başladıkça büyüyebilir. Aktivite alanlarının genişlemesi faillerin daha önceden bilinmeyen ya da hali hazırdaki farkındalık alanlarına yakın yerlerdeki yeni suç firsatlarını keşfetmesine neden olabilir.

Figür 2 bir failin (örn. ev sahibi takım taraftarı) aktivite ve farkındalık alanlarının (örn. ev, fast-food büfesi, bar ve stadyum), bir mağdurun (örn. deplasman takım taraftarı) aktivite alanı (örn. tren istasyonu, bar, fast-food büfesi ve stadyum) ile nasıl kesişebileceğinin basit bir örneğini göstermektedir. Suç deseni teorisi, bir suçun bir takım aktivite düğüm noktalarında (bar, fast-food büfesi ve stadyum) ya da bunları birbirine bağlayan güzergâhlarda (paths) bu fail ile mağdur arasındaki etkileşimin sonucu olarak ortaya çıkabileceğini ileri sürmektedir. Diğer bir ifadeyle, maçların oynandığı zamanlarda stadyum çevresindeki yerlerin ekolojisinin değişmesi normal koşullar altında bir araya gelmeyecek olan potansiyel fail/mağdur aktivite alanlarının birleşmesine olanak sağlar.

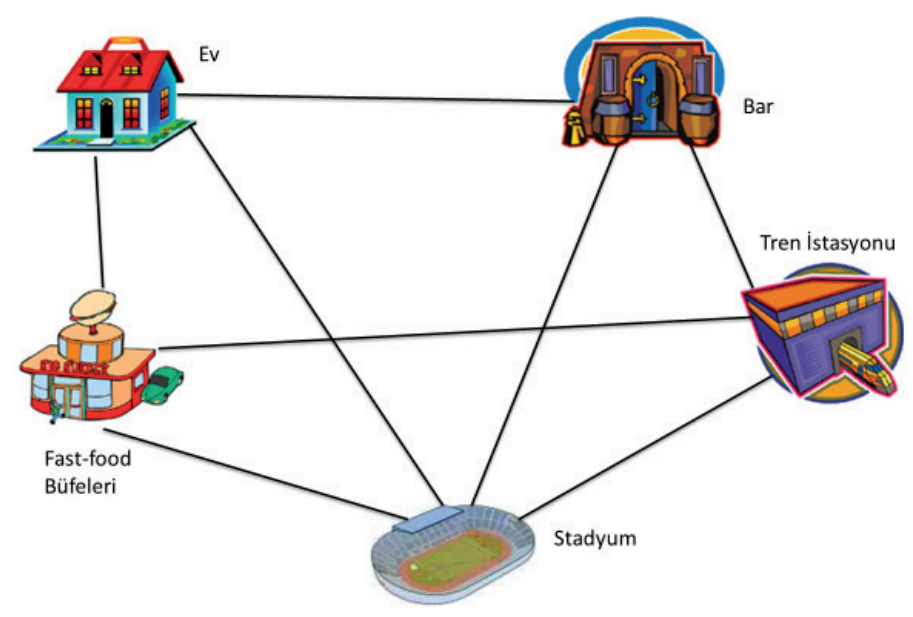

Figür 2. Fail ve mağdurların aktivite alanları örneği

$\mathrm{Bu}$ nedenledir ki, suç deseni teorisi neden suçun sıcak noktalarının (hotspots of crime) maç günleri stadyum çevresinde oluşabileceğini açıklayacak bir kavramsal çerçeve sunmaktadır (Brantingham ve Brantingham, 1999). Dahası, stadyum çevresinde bulunan aktivite düğüm noktalarını ve taraftarların zamansal hareketliliğini dikkate alarak, sıcak noktaların oluşabileceği belirli yerler ve bunların ne zaman ve neden oluşabilecekleri önceden kestirilebilecektir. 
Bu yaklaşımı daha da detaylandırmak gerekirse, futbol maçları futbol stadyumunun yakınındaki ve çevresindeki bölgede bulunan kişi sayısında bir artışa neden olacaktır. Tüm bu kişilerin fail, yakın tutucu (intimate handler), uygun hedef ve/veya ehil gardiyan (capable guardian) olmaları muhtemeldir. Artan kişi yoğunluğu ve rakip taraftarlar arasındaki etkileşim ile ortaya çıkabilecek provokasyon/tahrik nedeniyle (Branscombe ve Wann, 1992; Rotton, Olszewski, Charleton, ve Soler, 1978; Wortley, 2001; Russell, 2004) bu yerlerde suç beklenebilir bir durumdur. Bununla birlikte, ne insanların ne de suç aktivitesinin maç günleri ve diğer günlerdeki dağılımları eşit oranda olmaktadır. Daha ziyade, taraftarlar maçlara bir kısmı diğerlerinden daha fazla tercih edilen belirli güzargâhlardan geçerek ulaşacaklar ve suç için firsatlar sunan düğüm noktalarında bir araya geleceklerdir. Taraftarlar stadyuma maç başlamadan önce epizodik olarak ulaşır ve yine epizodik olarak maç sonucuna bağlı olarak bitiş düdüğünden sonra veya kısa bir süre önce stadyumdan ayrılırlar. Bu itibarla, futbol maçları eğer suç ve düzensizlik düzeyini etkiliyorsa, bu olayların günün diğer zamanları değil, belirli konumlarda maça yakın saatlerde, maç sırasında ve hemen maçın sonrasında ortaya çıkması beklenir.

Yakın zamana kadar, bu bakış açısı futbolla ilişkili suç ve düzensizlik bağlamında çok az ilgi görmüştür. Bu durum aslında anlaşılabilirdir çünkü ana akım kriminolojinin çoğu gibi, daha önce futbolla ilişkili suç ve düzensizlik sorunuyla ilgilenenler mekânlara değil, insanlara odaklanmışlardır (Eck ve Weisburd, 2005; Nettler, 1978; Sherman, 1995; Weisburd, 2002). Bununla birlikte, suçun mekânsal boyutuna olan ilginin artmaya başladığı söylenebilir (Breetzke ve Cohn, 2013; Kurland, 2014; Kurland vd., 2010; Kurland vd., 2013; Kurland vd., 2014; Madensen ve Knuttson, 2011). Bunun nedeni, k1smen, suçun içsel/doğal bir coğrafi niteliğe sahip olduğunun kabul edilmesi ve bu niteliğinin suçu önleme noktasında bilgi sağlıyor oluşudur. Örneğin, çevrede birçok ve çeşitli suç fırsatlarının bulunabilmesine rağmen, araştırmacılar (Sherman vd., 1989) tutarlı bir şekilde suçun yüksek oranda mekânsal olarak yoğunlaştığını ortaya koymuştur (Johnson vd., 2010). Aynı yönde, suçun en çok işlendiği yerlere polis kaynaklarının daha çok yönlendirilmesini de içeren "sıcak noktalama" politikasının suçun azalmasında etkili bir yöntem olduğu da defalarca dile getirilmiştir (Braga vd., 2014).

Bu doğrultuda, "sıcak nokta" haritalama, devriye ekiplerinin konuşlandırılması konusunda operasyonel brifingleri desteklemek amaciyla polis tarafindan kullanılan popüler bir suç önleme aracı olarak ortaya çıkmış (Hough ve Tilley, 1998), ve problem çözme ve istihbarat hizmetlerine bilgi sağlamıştır (Chainey ve Ratcliffe, 2005; Clarke ve Eck, 2005). Mevcut yüzlerce araştırma günlük suçları anlamlandırmada suç haritalama 
yönteminin yararlılığını incelemiş olmakla birlikte, söz konusu yaklaşım futbola ilişkin suç ve düzensizlik çalışmalarına nadiren uygulanmıştır. Bu makalede haritalama tam da bu konu ile ilişkili olarak kullanılmıştır. Elde edilen verilerin sunumundan önce, mekânsal suç desenleri çalışmalarında ortaya çıkan birkaç metodolojik soruna değinilecektir.

Bir dizi farklı sıcak nokta haritalama tekniği mevcut olmakla birlikte, Kernel Density Estimation/Kersel Yoğunluk Tahmini (KDE) günümüzde belki de en yaygın olarak kullanılan tekniktir. İdari sınırları kullanan tematik haritalamadan farklı olarak, KDE kesintisiz bir yüzey için "1sı haritaları (heat maps)" kullanır (bkz. Figür 4). KDE keyfi sınırları kullanmadığ için, , suç riskinin genellikle geniş bir alanda tekdüze olduğunu varsaymanın ekolojik yanlışlığı (bkz. Robinson, 1950) ve değiştirilebilir alansal birim problemi (Openshaw, 1984) de dahil olmak üzere tematik haritalama ile ilişkili bir takım sorunlar giderilmiş olmaktadır.

Bununla birlikte, suçun mekânsal desenini doğru bir şekilde yansitan bir suç haritası bile pratikte sınırlı olabilir. Örneğin, suç ne zamanda ne de mekânda durağan olmayan dinamik bir olgu olduğundan, polis memurlarının tüm gün için belirli yerlere tahsis edilebileceği veya tahsis edilmesi gerektiği gerçekçi bir varsayım değildir. Suçun mekânsal yoğunlaşması üzerine yapılan araştırmalar ile kıyaslandığında, suçun zamansal yoğunlaşması üzerine yapılan araştırmalar çok daha azdır (Johnson, Lab ve Bowers, 2008; Ratcliffe, 2002). Bununla birlikte, örneğin, animasyonlu haritaların kullanımı, haritaların bir zaman aralığından diğerine karşılaştırılması ve suç riskinin bir sıcak noktada zamanla nasıl değiştiğini göstermek için grafikler eklenmesi gibi suçların zamansal dağılımını anlamaya yönelik yöntemler benimsenmiştir (Ratcliffe, 2002).

Futbolla ilişkili suç ve düzensizliğin mekânsal ve zamansal boyutlarını analiz etmek bu konudaki anlayışı geliştirebilir ve güvenlik görevlilerinin ne zaman ve nerede görevlendirileceği hakkında rehberlik sağlayabilir. Kurland vd. (2014), örneğin, bu tarz bir analizi Wembley Stadyumu için gerçekleştirmiş ve suç riskinin maç günlerinde maçlardan hemen önce ve sonra ve stadyuma yakın yerlerde maç olmayan günlere kıyasla önemli derecede yüksek olduğunu ortaya koymuşlardır. Bu, yukarıda tartışılan teorinin test edilmesi anlamına gelmekle birlikte, analiz tipik bir futbol stadyumundan çok daha büyük olan ulusal bir stadyum içindi. Makalenin geri kalan bölümünde, benzer desenlerin Leeds United'ın futbol stadyumu için de geçerli olup olmadığ incelenecektir. İngiltere'nin kuzeyinde yer alan bu stadyum, milli takım maçlarından ziyade lig maçları için kullanılmaktadır. Yukarıda tartışılan teori eğer bir değer taşıyorsa, 
Wembley için gözlenenlere benzer desenler bu stadyum için de ortaya çıkmalıdır. Bir sonraki bölümde analiz edilen veriler açıklanacak, üretilen sonuçlar sunulacak ve yorumlanacaktır.

\section{Olay İncelemesi}

Bu çalışmada analiz edilen 2004-2010 yıllarında gerçekleşen hırsızlık suçlarına dair veriler Batı Yorkshire Polisi (WYP) ve İngiliz Ulaştırma Polisi (BTP) tarafından sağlanmıştır. Bu veriler 1 metrelik bir mekânsal çözünürlükte zaman damgalı (timestamped) ve coğrafi koordinatlar verilerek (geocoded) haritalanmış şekildedirler. Veriler, Leeds United (Elland Road) futbol stadyumunun merkezinin üç kilometre yarıçapında meydana gelmiş tüm kayıtlı hırsızlık olaylarını içermektedir (bkz. Figür 3).

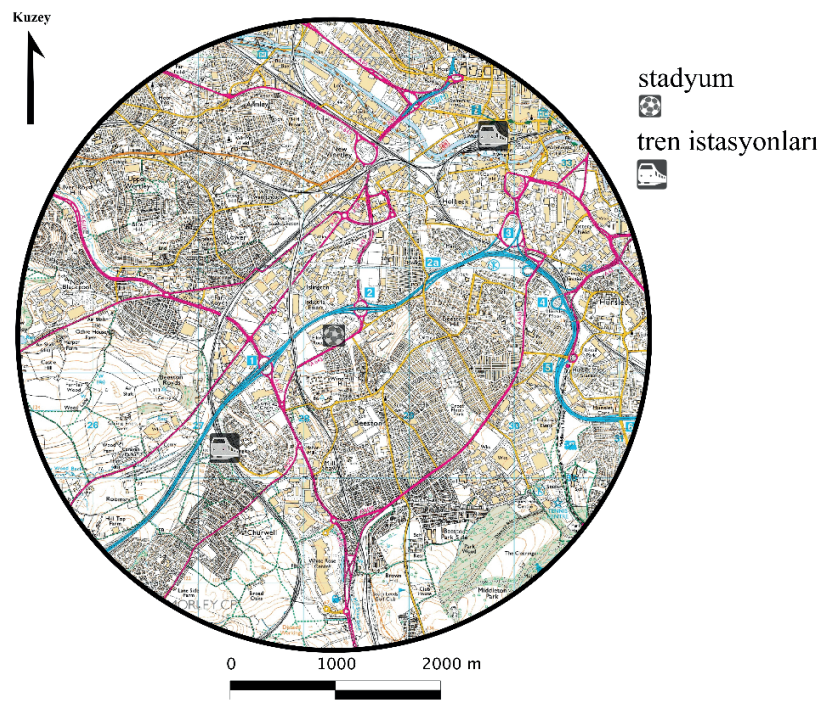

Figür 3. Leeds United (Elland Road) Stadyumu'nun inceleme alanı haritası

Futbol stadyumları epizodik olarak kullanıldığından, bu kullanımın suç üzerindeki etkisini tahmin etmek için, maç günleri ile maçın olmadığı günlerde aynı alanda nerede ve ne kadar suçun meydana geldiği karşılaştırılacaktır. 2004-2005 ve 2009-2010 futbol sezonları arasında stadyumda toplam 138 maç gerçekleşmiştir.

Araştırmalar, suç desenlerinde haftanın belli günlerine (Brunsdon ve Corcoran, 2006) ve yılın belli zamanlarına (Hird ve Ruparel, 2007) bağlı önemli farklılıklar gerçekleştiğini gösterdiğinden, maç günlerindeki suç desenleri maç oynanmayan benzer günlerdeki desenlerle karşılaştırılmıştır. Örneğin, kasım ayında bir cumartesi günü bir 
futbol karşılaşması gerçekleşmişse, futbol maçı olmayan en yakın veya onu takip eden cumartesi günü, "eşleştirilen karşılaştırma günü (paired comparison day)" olarak belirlenmiştir.

Maçtan sonra bir ay içindeki uygun karşıllaştırma günleri maç günlerinin yaklaş1k $\% 100$ 'ü $(\mathrm{N}=138)$ için belirlenmiştir. Bunların 125 'i yedi gün içinde, 10'u iki hafta içinde ve 3'ü de üç hafta içinde gerçekleşen günlerdir. Bu eşleştirilen tarih yaklaşımı (paired-date approach) doğal bir deneyi andırmakta ve suç desenlerinin maç günleri ile maç olmayan günlerde mekân ve zamanda nasıl farkl1lık gösterdiğini görmemize imkân sağlamaktadır.

İncelenen günlerde toplam 6.497 hırsızlık olayı meydana gelmiş̧tir. Bunların 3.403'ü maç günlerinde ve 3.094'ü ise karşılaştırma günlerinde ortaya çıkmıştır, ki bu veri maç günleri ile maç olmayan günler arasında stadyum çevresinde gerçekleşen hırsızlık düzeyinde bir farklı1ık olduğunu göstermektedir. Sonraki bölümlerde, maç ve maç dış1 günler için mekânsal ve zamansal desenlerdeki farkl1lıklar incelenecektir.

\section{Mekânsal Analizler}

Aşağıda, iki tip gün boyunca hırsızlık suçlarının mekânsal dağılımını incelemek için ilk olarak Kernel Yoğunluk Tahmini (KDE) kullanılacaktır. Ardından, hırsızlık suçlarının maç günleri ve karşılaştırma günlerinde mekânsal desenlerindeki farklılıklarını tespit etmek için kullanılan istatistiksel yaklaşım tartışılacaktır. Bu metodoloji, maç günlerinde suçun normalden daha yüksek olduğu yerleri tespit etmede güvenilir bir yol sağlamakta ve bu da polisin, maç günü en çok ihtiyaç duyulan yerlerde kaynaklarını daha iyi bir şekilde kullanmasına imkân sağlamaktadır.

\section{Kernel Yoğunluk Tahmini}

Yukarıda belirtildiği üzere, bölgeye dayalı bir suç riski sınıflandırması yapmak yerine, Kernal Yoğunluk Tahmini (KDE) kesintisiz bir sıcak nokta yüzeyi oluşturmak için düzeltici bir yöntem kullanmaktadır. Figür 4, hırsızlık suçlarının genel dağılımının maç ve maç dışı günlerde benzer olduğunu, ancak bazı fark edilebilir ve önemli farkl11ıkların bulunduğunu göstermektedir.

Özellikle, maç günü hırsızlıklarının (maç dışı günlerdeki hırsızlıklardan farklı olarak) Elland Road Stadyumu'nun kısmen güneydoğu, doğu ve kuzeydoğusunda daha çok yoğunlaştığı (daha koyu sarımsı turuncu renklerle kanıtlandığ1 üzere) görülmektedir. Dahası, maç günü haritasının sağ üst tarafında futbol taraftarlarının 
futbol sahasına giderken geçtiği güzergâha denk gelen biraz daha koyu kırmızımsı bir renk var. Bu örüntü, bu yerlerde maç günleri daha fazla sayıda insan ve dolayısıyla daha fazla suç firsatı bulunduğundan yukarıda tartışılan teori ile uyumludur.
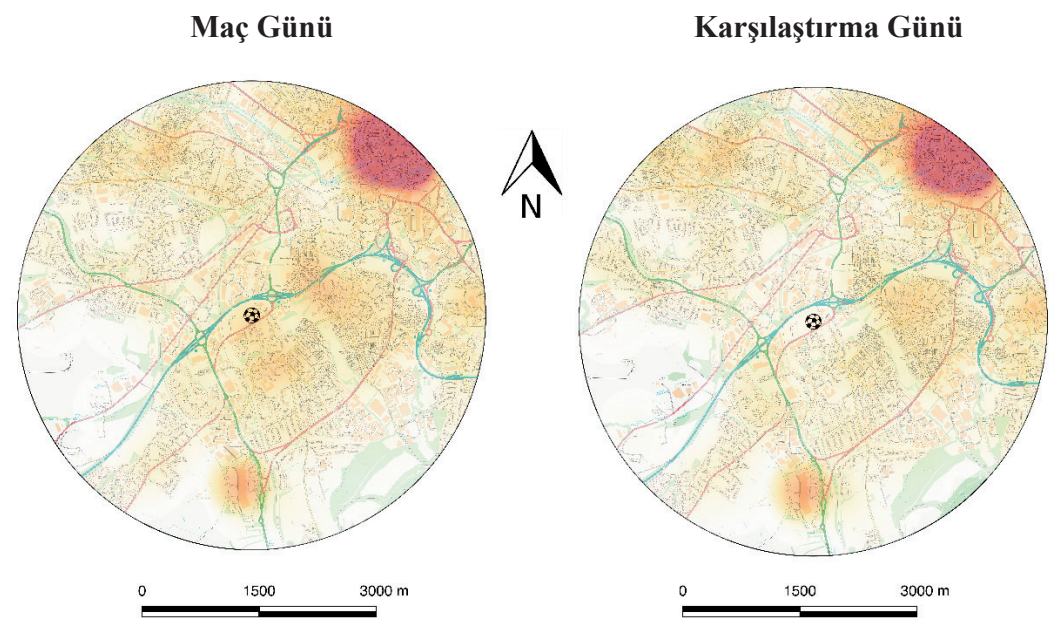

Figür 4. Elland Road Futbol Stadyumu çevresindeki hırsızlık suçlarının maç ve maç dışı günlerdeki mekânsal dağılımı

NOT: İki tip gündeki mekânsal desenler arasındaki farklılıkları vurgulamaya yardımcı olması için her iki harita için de aynı tematik ölçek kullanılmıştır.

Bununla birlikte, desenlerin görsel incelemesi yanıltıcı olabilir. Sonuç olarak, algılanan farklılıkların güvenilir olup olmadığını belirlemek önemlidir. Bunu yapmak için de, Figür 4'te gösterilen desenlerde algılanan farklılıkların güvenilir olup olmadığını (istatistiksel anlamda) belirlemek için bir uzaysal permütasyon (spatial permutation) testi geliştirilmiştir.

\section{Uzaysal Permütasyon Testi (Spatial Permutation Test)}

Testin temel düşüncesi, hırsızlık suçlarının mekânsal dağılımında gözlenen farklılıkların anlamlı olup olmadığını veya rastlantısal değişikliklerle ortaya çıkıp çıkmadıklarını tahmin etmektir. Bunu belirlemek için, incelenen alan ilk olarak nispeten sıkı bir uzaysal ızgara ( $g r i d$ ) kullanılarak bölünmüş ve gridin her bir hücresindeki suç hacmi maç günleri ve maç dışı günler için ortaya çıkarılmıştır. Farkların güvenilir olup olmadığı, parametrik olmayan bir permütasyon testi kullanılarak belirlenmiştir. Bu yaklaşımın içerdiği aşamalar aşağıda detaylandırılmıştır: 
1. İncelenen alanı mutat büyüklükteki hücrelerden (çalışmamızda $100 \mathrm{~m}^{2}$ ) oluşan bir grid kaplamaktadır.

2. Maç ve maç dışı günler için her bir grid hücresine düşen suç sayısı belirlenmiştir.

3. Gözlemlenen farklılıkların global bir indeksini oluşturmak için, Denklem (1) uyarınca, her bir maç günü ve ilgili karşılaştırma gününde grid hücrelerdeki suç sayılarındaki farkların toplamı hesaplanmıştır:

$$
D_{i}=\sum_{i=1}^{N}\left(M_{i}-C_{i}\right) \quad \text { Denklem (1), }
$$

Denklemde $N$ toplam grid hücre sayısını, $i$ göz önünde tutulan grid hücresini, $M_{\mathrm{i}}$ maç günleri $i$ grid hücresindeki hırsızlık suçlarının sayısını ve $C_{\mathrm{i}}$ de karşılaştırma (comparison) günleri $i$ grid hücresindeki suç sayısını göstermektedir.

4. Karşılaştırma yapmak için, sıfır hipotez altında her bir grid hücresi için beklenen bir dağılım hesaplanmıştır. Sıfır hipotez, bir grid hücresinde meydana gelen her suçun bir maç gününde veya karşılaştırma gününde ortaya çıkabileceğine dair eşit olasıllk olduğunu ifade eder.

5. Dördüncü aşamada üretilen veri kullanılarak üçüncü aşama tekrar edilir. Bu alı̧şırmanın bir kez tamamlanması, $D_{i}$ test istatistiklerinin beklenen dağılımının bir değerini hesaplamak için kullanılabilecek verilerin bir permütasyonunu sağlar. Bu alıştırmanın birçok kez tekrarlanması, ki bu çalışmada 999 kez tekrarlanmıştır, sıfır hipotezinin varsayımları altında oluşturulan $D_{i}$ istatistiğinin dağılımını tahmin etmeyi sağlayan Monte Carlo (MC) simülasyonunu temsil eder.

6. Her grid hücresi için gözlenen farklılıkların istatistiksel önemi belirlenir. Her alan için gözlemlenen $D_{i}$ istatistiklerinin istatistiksel önemi, hesaplanan $D_{i}$ değerlerini aşan zamanların oranının hesaplanmasıyla tahmin edilebilir. Biz usulen Curtis ve Sham'ın (2002) denklemini (Denklem (2)) kullanıyoruz:

$p=\frac{r+1}{n+1} \quad$ Denklem (2),

Bu denklemde $r$, en az, gözlemlenen $D_{\mathrm{i}}$ değeri kadar büyük olan devşirilen veriler (permuted data) için $D_{\mathrm{i}}$ değerlerinin sayısıdır, ve $n$ ise kullanılan permütasyonların sayısıdır (bizim çalışmamızda bu 999'dur).

7. İstatistiksel olarak anlamlı/önemli olmayan $D_{\mathrm{i}}$ test istatistiklerinin gözlemlendiği grid hücreleri 0 puan (farksız) olarak belirlenmiştir. İstatistiksel olarak anlamlı 
olanlara, gözlemlenen sayının beklenenden daha yüksek olması durumunda 1 puan ve daha az olması durumunda 2 puan verilmiştir. Çoklu karşılaştırmalar problemini ortadan kaldırmak için bir Bonferroni düzeltmesi uygulanmış ve böylece Tip I hatasının toplam riski \% 5'te tutulmuştur.

Yedinci aşama analiz sonuçlarının bir harita üzerinde kolayca özetlenmesini sağlar. Figür 5, maç günlerinde maç dışı günlere kıyasla (istatistiksel olarak) önemli derecede daha çok sayıda hırsızlık olayının olduğu alanları göstermektedir. Bu, stadyum etrafındaki artan hırsızlık riskinin (zaman birimi başına) şehir merkezindeki birkaç yerin yanı sıra bazı (tüm değil) stadyuma yakın yerlerde de bulunduğunu göstermektedir. Pratik çıkarımlar açısından, maç günlerinde bu tür yerlere ek polis kaynakları tahsis edilebilir. Kuşkusuz, başka suçların yoğunlaştığı bilinen nispeten küçük alanların belirlenmesi, aynı zamanda, maç günlerinde mağaza hırsızları (shoplifters) tarafından mağdur edilen bu alanlardaki mağazalara yönelik çeşitli müdahale tipleri hakkında fikir üretmeye de yardımcı olabilir. Buna ek olarak, maç günlerinde diğer yakın yerlerde değil de bu belirli yerlerde suç sayısında artış gerçekleştiğini açıklamak için daha fazla analiz yapılabilir. Bu tür bir analiz, suçun azaltılması için diğer müdahaleler (geçici veya değil) yoluyla etkilenebilecek durumsal faktörleri ortaya çıkarabilir. Sonraki bölümde, hırsızlık suçlarının zamanlamasının maç günleri ve maç dışı günlerde farklılaşıp farklılaşmadığ incelenecektir.
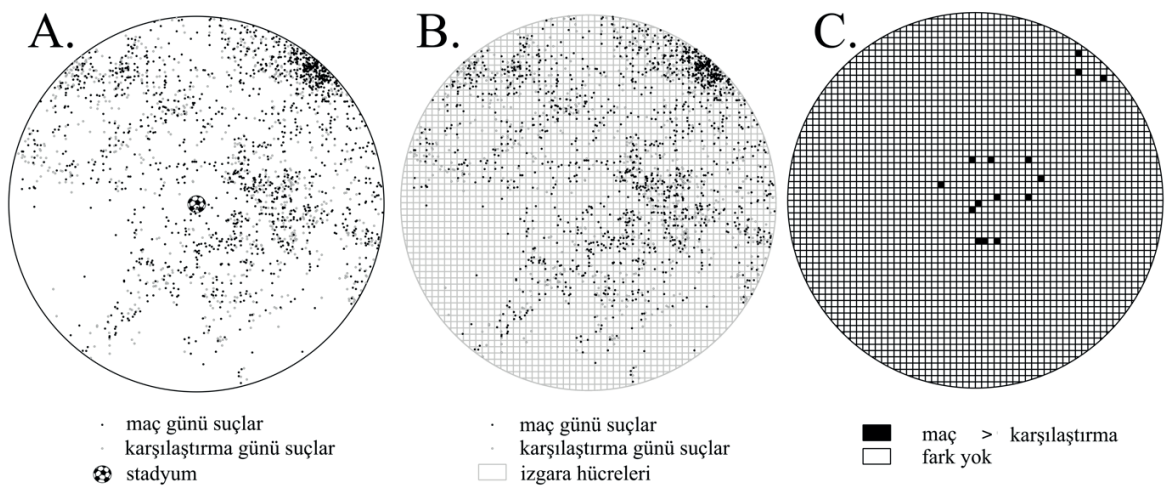

Figür 5. (A) Elland Road Stadyumu etrafındaki hırsızlıkların maç günü ve karşılaştırma günlerinde mekânsal nokta deseni, (B) İnceleme alanı üzerine yerleştirilmiş ve maç günleri

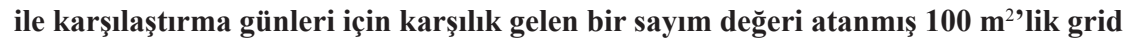
hücreleri, (C) Stadyum çevresindeki $100 \mathrm{~m}^{2}$ 'lik alanda karşılaştırma günlerinin aksine, maç günlerinde, önemli ölçüde daha fazla suç sayısının $(p<0.05)$ olduğu yerleri göstermek için haritalandırılmış uzaysal permütasyon testinden elde edilen sonuçlar. 


\section{Zamansal Analizler}

\subsection{Maç Ayarlı Zamansal Analiz}

Hırsızlık suçlarının zamanlamasının maç günü ve maç dışı günlerde değişip değişmediğini ve değişiyorsa nasıl değiştiğini incelemenin bir yolu, iki tip gün için suç riskinin saatlik değişimini (her saat başına suç miktarı) incelemektir. Bu yöntemde ortaya çıkan problem maçların farklı günlerde farklı zamanlarda başlayıp bitmesidir. İki tür gün için saat başına suç sayımını gösteren basit bir birleştirilmiş analiz bu varyasyonu yok saymakta ve gerçekte neler olup bittiğini maskelemektedir.

Bundan dolayıdır ki, maç ve karşılaştırma günlerinde suçların meydana geldiği gerçek zamanlardaki değişikliği analiz etmek yerine, hırsızlık olaylarının meydana geldiği zamanlamadaki değişiklikleri maçların oynandığı zamana bağlı olarak inceliyoruz. Bu amaçla, her gün için, maçların başladığı zamana göre hırsızlık suçlarının meydana geldiği zamanları temsil edecek yeni zamansal göstergeler üretilmiştir.

Örneğin, başlaması öğle saatine (12.00) denk gelen bir maç için, saat 11:00'da meydana gelen hırsızlık olayları, maç başlamadan bir saat önce gerçekleştiklerini göstermek için belirli değerlere atanabilir. Aynı şekilde, aynı maçta saat 13:00'da meydana gelen hırsızlık olayları, maç başladıktan bir saat sonra gerçekleştiklerini göstermek için belirli değerlere atanacaktır. Bu yöntem hem maç hem de karşıllaştırma günleri için kullanılmış; her karşılaştırma gününe, ilgili maç gününe göre bir (nispi) zaman tahsis edilmiştir. Bu süreç, maç başlamadan önceki ve sonraki 11 saat boyunca gerçekleştirilmiş ve sonuçlar Figür 6'da gösterilmiştir.

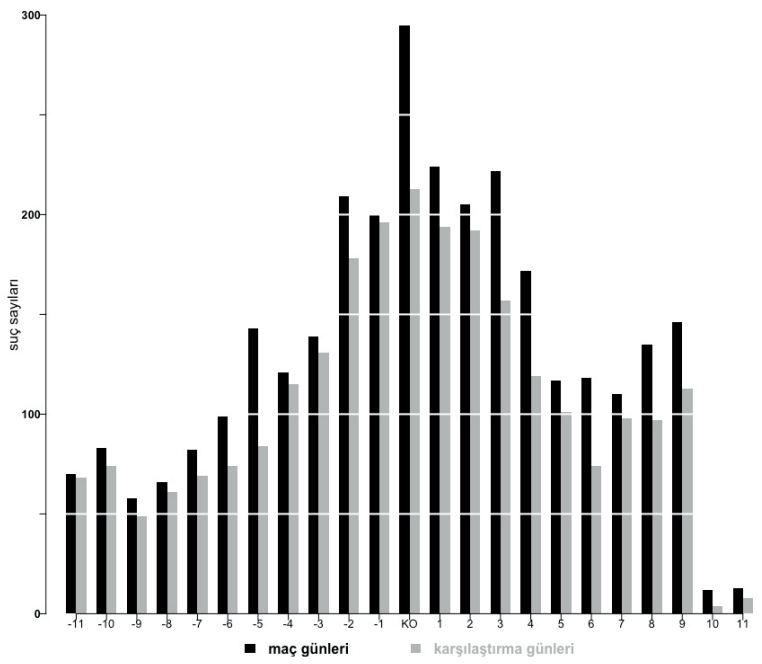

Figür 6. Maç ve karşılaştırma günleri hırsızlıkları için maç başlama saati ayarlı zamansal frekans 
Figür 6, tahmin edildiği gibi, maç günlerinde maç başlamadan önce, maç sırasında ve sonrasında daha fazla hırsızlık suçunun meydana geldiğini göstermektedir. Gözlemlenen desenlerin istatistiksel anlamlılı̆̆ını ve farklılıkların devam ettiği süreyi tahmin etmek için, yukarıda tartışılan permütasyon yaklaşımı kullanılmıştır (grid hücre sayımlarını saatlik sayımlarla değiştirerek). Bu, maç başlamadan beş saat önce başlayan dokuz saatlik periyotta maç günlerinde yüksek (elevated) miktarda hırsızlık olayının ( $\mathrm{p}=0.001)$ olduğunu göstermiştir. Bu periyotta, aynı periyotta karşılaştırma günlerinde gerçekleşen 1.377 hırsızlık suçuna karşılık, maç günlerinde 1.635 hırsızlık suçu yaşanmıştır. Bu nedenle analiz, girişte tartışılan teorik yaklaşıma destek sağlar ve polisin (veya diğer) kaynaklarının maç günlerinde suçu önlemek için en iyi şekilde kullanılabileceği periyodu ortaya çıkarır.

\section{Tartışma ve Sonuç}

Bu makalede, futbol maçlarıyla ilişkili hırsızlığı anlamak ve ele almak için tarihsel yaklaşımları gözden geçirdik ve tartışılan noktaları göstermek için olay incelemesi yöntemini kullanarak bu sorunun çevresel kriminoloji merceğinden nasıl anlaşılabileceğini ortaya koyduk. Sunulan analizler suçun — en azından bu olay incelemesindeki alan için — mekân ve zamanda (maç ve maç dışı günlerde) rastgele dağılmadığını ve maç günlerindeki suç dağılımının diğer günlerdeki suç dağılımını yansıtmadığını göstermektedir. Sunulan örnekte, hırsızlık riskinin (zaman birimi başına), maç günlerinde stadyumun yakınındaki belirli yerlerde ve maç öncesinde, sırasında ve sonrasındaki bir zaman penceresi için özellikle yüksek olduğu bulunmuştur.

Olayların maç günlerinde mekân ve zamanda belirgin kümelenmesi göz önüne alındığında, maç günlerinde sıcak noktalama polislik stratejilerinin benimsenmesi, bu tür suçların azaltılmasına yardımcı olabilecek en belirgin yaklaşımlardan biri olarak ortaya çıkmaktadır. Sıcak nokta polisliğinin günlük kentsel suçları azaltmada etkili olduğu gösterilmiş olsa da, farkında olduğumuz kadarıyla bu tür stratejilerin futbol maçlarında etkinliğinin değerlendirildiği çalışmalar mevcut değildir. En azından Birleşik Krallık’ta, polis memurları maç günleri muhakkak futbol stadyumlarına yerleştirilmekte ve fakat - bilgimiz dahilinde olduğu kadarıyla - devriye planları bu çalışmada sunulan detaylı analizlerle bilgilendirilmemektedir. Dahası, sıcak nokta polislik stratejileri çeşitli biçimlerde olabilir ve farklı yaklaşımlar farklı kontekstlerde farklı etkilere sahip olabilir (güncel bir tartışma için bkz. Johnson vd., 2015). Örneğin, polis görünürlüğü bazı durumlarda suçun işlenmesini tek başına önleyebilir. Bazı durumlarda ise yasa ve düzeni uygulamak için daha kinetik bir rol gerekebilir. Basitçe 
söylemek gerekirse, futbol maçlarındaki sıcak nokta polisliklerinin etkinliğine veya hangi yaklaşımların en iyi şekilde çalışabileceğine dair çok az kanıtımız var, ancak burada gözlemlenen hırsızlık desenleri suçla mücadelede coğrafi-odaklı yaklaşımların kesinlikle mantıklı olduğunu gösteriyor.

Yukarıda tartışıldığı üzere, diğer suç azaltma stratejileri durumsal müdahaleler içerebilir. Örneğin, maçlar bittikten sonra her iki taraftarın kullandığı ulaşım noktalarında kayda değer miktarda daha fazla hırsızlık meydana geliyorsa, ev sahibi ve deplasman taraftarlarının etkileşimlerini sınırlamak ve artan insan sayısının oluşturduğu firsatları azaltmak için taraftarların stadyumu terk etme şeklini kademeli olarak düzenlemek bir strateji olabilir. Bu, stadyumların tasarımı yoluyla ve/veya taraftarlar stadyumu terk ederken fiziken onlara engel olarak hayata geçirilebilir.

Sonuç olarak, günlük suçlarda olduğu gibi, en azından burada sunulan olay incelemesi için (ayrıca bkz. Kurland, 2014; Kurland vd., 2010; 2013; 2014; 2018), futbol maçlarıyla ilişkili hırsızlık suçu belirli bir zaman ve mekânda toplanmaktadır. Gelecekteki araştırmalar bu bulguların dışsal geçerliliğini belirlemek üzerine kurulabilir, ancak şimdilik bu araştırma coğrafi-odaklı müdahalelerin - fail odaklılardan ziyade ya da onların yanı sıra - futbol maçlarıyla ilişkili suçları azaltma potansiyeline sahip olduğunu göstermektedir. Hangi yaklaşımın en etkili ve en uygun maliyetli olduğunu belirlemek gelecekteki araştırmalar için bir gündem oluşturmaktadır.

Finansal Destek: Yazarlar bu çalışma için finansal destek almamışlardır.

\section{Kaynakça}

Armstrong, G. (1998), Football Hooligans: Knowing the Score. Oxford: Berg.

Branscombe, N. R. \& Wann, D. L. (1992), 'Role of Identification with a Group, Arousal, Categorization Processes, and Self-Esteem in Sports Spectator Aggression', Human Relations, 45(10): 1013-1033.

Braga, A. A., Papachristos, A. V. \& Hureau, D. M. (2014), 'The Effects of Hot Spots Policing on Crime: An Updated Systematic Review and Meta-Analysis', Justice Quarterly, 31(4): 633-663.

Brunsdon, C. \& Corcoran, J. (2006), 'Using Circular Statistics to Analyse Time Patterns in Crime Incidence', Computers, Environment and Urban Systems, 30(3): 300-319.

Brantingham, P. L. \& Brantingham, P. J. (1981), 'Notes on the Geometry of Crime', Environmental Criminology, 27-54.

Brantingham, P. L. \& Brantingham, P. J. (1984), 'Mobility, Notoriety and Crime: A study of Crime Patterns in Urban Nodal Points', Journal of Environmental Systems, 11(1): 89-99.

Brantingham, P. L. \& Brantingham, P. J. (1993), 'Nodes, Paths and Edges: Considerations on the Complexity of Crime and the Physical Environment', Journal of Environmental Psychology, 13(1): 3-28.

Brantingham, P. L. \& Brantingham, P. J. (1999), ‘A Theoretical Model of Crime Hot Spot Generation', Studies on Crime and Crime Prevention, 8: 7-26. 
Breetzke, G. \& Cohn, E. G. (2013), 'Sporting Events and the Spatial Patterning of Crime in South Africa: Local Interpretations and International Implications', Canadian Journal of Criminology and Criminal Justice/La Revue Canadienne de Criminologie et de Justice Pénale, 55(3): 387-420.

Brunsdon, C. \& Corcoran, J. (2006), 'Using Circular Statistics to Analyse Time Patterns in Crime Incidence', Computers, Environment and Urban Systems, 30(3): 300-319.

Buford, B. (1991), Among the Thugs. London: Random House.

Chainey, S. \& Ratcliffe, J. (2005), GIS and Crime Mapping. Chichester: John Wiley \& Sons.

Clarke, R. V. G. \& Eck, J. E. (2005), Crime Analysis for Problem Solvers in 60 Small Steps. Washington, DC: Office of Community Oriented Policing Services, US Department of Justice.

Cohen, L. E. \& Felson, M. (1979), 'Social Change and Crime Rate Trends: A Routine Activity Approach', American Sociological Review, 44(4): 588-608.

Cornish, D. B. \& Clarke, R. V. (1986), The Reasoning Criminal: Rational Choice Perspectives on Offending. New York: Springer.

De Vreese, S. (2000), 'Hooliganism Under the Statistical Magnifying Glass: A Belgian Case Study', European Journal on Criminal Policy and Research, 8: 201-23.

Dunning, E. (1999), Sport Matters: Sociological Studies of Sport, Violence, and Civilization. Routledge: Chapman \& Hall.

Dunning, E., Murphy, P. \& Williams, J. M. (1988), The Roots of Football Hooliganism: An Historical and Sociological Study. London: Routledge \& Kegan Paul.

Eck, J. E. (1994), Drug Markets and Drug Places: A Case-control Study of the Spatial Structure of Illicit Drug Dealing. Yayınlanmamıs Doktora Tezi. University of Maryland, Faculty of the Graduate School.

Eck, J. E. (2003), 'The Complexity of Problem Theory, Research and Evaluation', in J. Knutsson (Ed.) ProblemOriented Policing: From Innovation to Mainstream Crime Prevention Studies. Monsley, NY: Criminal Justice Press.

Eck, J. E. \& Weisburd, D. (1995), Crime and Place: Crime Prevention Studies. Monsley, NY: Willow Tree Pr.

Elias, N. \& Dunning, E. (1971), 'Folk Football in Medieval and Early Modern Britain', The Sociology of Sport, 116-132.

Felson, M. (1986), 'Linking Criminal Choices, Routine Activities, Informal Control, and Criminal Outcomes', in Cornish, D. B. \& Clarke, R. V. (Eds.) The Reasoning Criminal: Rational Choice Perspectives on Offending. New York: Springer.

Felson, M. (1995), 'Those Who Discourage Crime', in Eck J. \& Weisburd D. (Eds.) Crime Prevention Studies - Volume 4. Monsey, NY: Criminal Justice Press.

Felson, M. \& Cohen L. (1980), 'Human Ecology and Crime: A Routine Activity Approach', Human Ecology, 8: 389-406.

Fitz-Stephen, W. (1961), Fitz-Stephen's Description of the City of London. London: B. White.

Frosdick, S. \& Marsh, P. (2005), Football Hooliganism. London: Taylor \& Francis.

Harrison, P. (1974), 'Soccer's Tribal Wars', New Society, 29(622): 602-604.

Hird, C. \& Ruparel, C. (2007), Seasonality in Recorded Crime: Preliminary Findings. Home Office.

Home Office (2004), Home Office Statistics on Football-Related Arrests and Banning Orders: Season 2003/2004. https://www.gov.uk/government/collections/football-banning-orders Erişim: 2 Kasım 2010.

Home Office (2005), Home Office Statistics on Football-Related Arrests and Banning Orders: Season 2004/2005. https:/www.gov.uk/government/collections/football-banning-orders Erişim: 2 Kasım 2010.

Home Office (2006), Home Office Statistics on Football-Related Arrests and Banning Orders: Season 2005/2006. https://www.gov.uk/government/collections/football-banning-orders Erişim: 2 Kasım 2010.

Home Office (2007), Home Office Statistics on Football-Related Arrests and Banning Orders: Season 2006/2007. https:/www.gov.uk/government/collections/football-banning-orders Erişim: 2 Kasım 2010. 
Home Office (2008), Home Office Statistics on Football-Related Arrests and Banning Orders: Season 2007/2008. https://www.gov.uk/government/collections/football-banning-orders Erişim: 2 Kasım 2010.

Home Office (2009), Home Office Statistics on Football-Related Arrests and Banning Orders: Season 2008/2009. http:// www.homeoffice.gov.uk/documents/football-arrests-08092835.pdf?view1/4Binary. Erişim: 2 Kasım 2010 .

Johnson, S. D. (2010), ‘A Brief History of Crime Concentration', European Journal of Applied Mathematics, 21: $349-370$.

Johnson, S. D., Lab, S. P. \& Bowers, K. J. (2008), 'Stable and Fluid Hotspots of Crime: Differentiation and Identification', Built Environment, 34(1): 32-45.

Johnson, S. D., Tilley, N. \& Bowers, K. J. (2015), 'Introducing EMMIE: An Evidence Rating Scale to Encourage Mixed-Method Crime Prevention Synthesis Reviews', Journal of Experimental Criminology, 11: 459-473.

Kurland, J. (2014), The Ecology of Football-Related Crime and Disorder. Yayınlanmamıs Doktora Tezi. University College London, London.

Kurland, J., Johnson, S. D. \& Tilley, N. (2010), Late Weekend Kick-offs at Premier Football Matches and their Possible Link to Increased Levels of Alcohol-related ASB and Disorder. London: Government Office for London.

Kurland, J., Johnson, S. D. \& Tilley, N. (2013), 'Offenses around Stadiums: A Natural Experiment on Crime Attraction and Generation', Journal of Research in Crime and Delinquency, 51(1): 5-28.

Kurland, J., Tilley, N. \& Johnson, S. D. (2014), 'A Football Hotspot Matrix: A Framework for Targeting of Football-related Crime and Disorder’, in Hopkins, M. \& Treadwell, J. (Eds.) Football Hooliganism, Crime and Crowd Management: Contemporary perspectives in Relation to Research and Theory. London: Palgrave MacMillan.

Kurland, J., Tilley, N. \& Johnson, S. D. (2018), 'Football Pollution: An Investigation of Spatial and Temporal Patterns of Crime in and around Stadia in England', Security Journal, 31(3): 665-684.

Lösel, F. \& Bliesener, T. (2003), 'Hooligan Violence: A Study on Prevale, Origins and Prevention', in F. Dünkel \& K. Drenkhahn (Eds.) Youth Violence: New Patters and Local Responses - Experiences in East and West. Mönchengladbach: Forum Verlag Godesberg.

Madensen, T. D. \& Eck, J. E. (2011), 'Crowd-Related Crime: An Environmental Criminological Perspective', in T. D. Madensen \& J. Knutsson (Eds.) Preventing Crowd Violence. Boulder: Lynne Rienner.

Madensen, T.D. \& Knutsson, J. (2011), Preventing Crowd Violence. Boulder: Lynne Rienner.

Marples, M. (1954), A History of Football. Londra: Secker \& Warburg.

Marsh, P.E. (1978), Aggro: The Illusion of Violence. Londra: Dent.

Nettler, G. (1978), 'Social Status and Self-Reported Criminality’, Social Forces, 57(1): 304-305.

North, B. V., Curtis, D. \& Sham, P. C. (2002), 'A Note on the Calculation of Empirical P Values from Monte Carlo Procedures', American Journal of Human Genetics, 71(2): 439-441.

Openshaw, S. (1984), The Modifiable Areal Unit Problem. Geo Abstracts University of East Anglia.

Ratcliffe, J.H. (2002), 'Aoristic Signatures and the Spatio-Temporal Analysis of High Volume Crime Patterns', Journal of Quantitative Criminology, 18(1): 23-43.

Ratcliffe, J. H. (2004), 'The Hotspot Matrix: A Framework for the Spatio-Temporal Targeting of Crime Reduction', Police Practice and Research, 5(1): 5-23.

Reppetto, T.A. (1974), Residential Crime. Cambridge: Ballinger Publishing Company.

Robson, G. (2000), 'No One Likes Us, We Don"t Care': The Myth and Reality of Millwall Fandom. Oxford: Berg.

Rossmo, K. D. (2000), Geographic Profiling. Boca Raton: CRC Press.

Rossmo, K. D., Laverty, I. \& Moore, B. (2004), 'Geographic Profiling for Serial Crime Investigation', in F. Wang (Ed.) Geographic Information Systems and Crime Analysis. Hershey: Idea Group. 
Rotton, J., D. Olszewski, M. Charleton, and E. Soler. (1978), 'Loud Speech, Conglomerate Noise, and Behavioral Aftereffects', Journal of Applied Psychology, 63(3): 360-365.

Russell, G.W. (2004), 'Sport Riots: A Social-Psychological Review', Aggression and Violent Behavior, 9(4): 353-378.

Scott, M. S., Eck, J. E., Knutsson, J. \& Goldstein, H. (2008), 'Problem-Oriented Policing and Environmental Criminology’, in R. Wortley \& L. Mazerolle (Eds.) Environmental Criminology and Crime Analysis. Londra: Willan.

Sherman, L.W. (1995), 'Hot Spots of Crime and Criminal Careers of Places', in J. E. Eck \& D. Weisburd (Eds.) Crime and Place: Crime Prevention Studies. Monsey: Willow Tree.

Sherman, L.W., Gartin, P. R., \& Buerger, M. E. (1989), 'Hot Spots of Predatory Crime: Routine Activities and the Criminology of Place', Criminology, 27(1): 27-56.

Stott, C. \& Pearson, G. (2006), 'Football Banning Orders, Proportionality, and Public Order Policing', The Howard Journal of Criminal Justice, 45(3): 241-254.

Strutt, J. (1801), The Sports and Pastimes of the People of England from the Earliest Period: Including the Rural and Domestic Recreations, May Games, Mummeries, Pageants, Processions and Pompous Spectacles. Londra: Methuen \& Company.

Taylor, I. (1971), ‘A Speculative Sociology of Football Hooliganism', in E. Dunning (Ed.) The Sociology of Sport: A Selection of Readings. London: Cass.

Tekin (2019), Türk Futbolunda Durumsal Suç Önlemenin Kriminolojik Bir Değerlendirmesi, İstanbul: Legal Yayıncilik.

Townsley, M. \& Sidebottom, A. (2010), 'All Offenders Are Equal, but Some Are More Equal Than Others: Variation in Journeys to Crime Between Offenders', Criminology, 48(3): 897-917.

Weisburd, D. (2002), 'From Criminals to Criminal Contexts: Reorienting Crime Prevention Research and Policy', Crime and Social Organization: Advances in Criminological Theory, 10: 197-216.

Wortley, R. (2001), 'A Classification Technique for Controlling Situational Precipitators of Crime', Security Journal, 14: 63-82. 